\title{
O estudo das migrações a partir da Psicologia Social: Uma perspectiva crítica
}

\section{The study of migrations from Social Psychology: A critical perspective}

\section{El estudio de las migraciones a partir de la Psicología Social: Una perspectiva crítica}

\author{
Suélen Cristina de Miranda* \\ Pontifícia Universidade Católica de São Paulo - PUC/SP, São Paulo, São Paulo, Brasil
}

\begin{abstract}
RESUMO
A partir da perspectiva da chamada "Psicologia Social Crítica", este artigo toma como base o sintagma identidade-metamorfose-emancipação, desenvolvido por Antônio da Costa Ciampa, para discutir a necessária desnaturalização do termo migrante, cuja vivência singular sempre será atravessada por referências de classe, gênero, raça/etnicidade e nacionalidade. Explicita-se o imperativo de um deslocamento de olhar do processo migratório em si para o migrante que, enquanto sujeito, atribui significados e sentidos particulares aos diversos condicionamentos a que está exposto a partir de suas histórias e projetos de vida. Em vista disso, o presente trabalho propõe um enfoque que supere as dicotomias existentes entre as abordagens micro e macroestruturais, considerando a percepção singular do migrante com relação às determinações históricas, políticas, econômicas, sociais e culturais envolvidas tanto no lugar de origem quanto de destino. Para tanto, foi feita uma revisão bibliográfica acerca das contribuições históricas de alguns importantes autores da temática migratória, além da diferenciação entre as principais teorias desenvolvidas sobre esse fenômeno, para que seja possível a compreensão da abordagem proposta e sua relação com os estudos migratórios.
\end{abstract}

Palavras-chave: migração, teorias, Psicologia Social Crítica, identidade.

\begin{abstract}
From the perspective of the so-called "Critical Social Psychology", this article is based on the syntagm identity-metamorphosis-emancipation, developed by Antônio da Costa Ciampa, to discuss the necessary denaturalization of the term migrant, whose unique experience will always be crossed by references of class, gender, race/ethnicity and nationality. The imperative of a shifting of the view of the migratory process itself to the migrant, who, as subject, attributes meanings and particular senses to the various conditions to which he is exposed from his stories and life projects. Considering this, the present work proposes an approach that overcomes the existing dichotomies between the micro and macro-structural perspectives, considering the singular perception of the migrant in relation to the historical, political, economic, social and cultural determinations involved in
\end{abstract}


the place of origin and of destination. To do so, it was made a bibliographical review about the historical contributions of some important authors of the migratory theme, besides the differentiation between the main theories developed on this phenomenon, to understand the proposed approach and its relation with the migratory studies.

Keywords: migration, theories, Critical Social Psychology, identity.

\begin{abstract}
RESUMEN
Desde la perspectiva de la llamada "Psicología Social Crítica", este artículo se basa en el sintagma identidad-metamorfosis-emancipación, desarrollado por Antônio da Costa Ciampa, para discutir la necesaria desnaturalización del término migrante, cuya vivencia singular siempre será atravesada por referencias de clase, género, raza/etnicidad y nacionalidad. Es explícito el imperativo de un desplazamiento de una mirada del proceso migratorio en sí al migrante que, como sujeto, atribuye significados y sentidos particulares a los diversos condicionamientos a que está expuesto desde sus historias y proyectos de vida. En vista de ello, el presente trabajo propone un enfoque que supere las dicotomías existentes entre los enfoques micro y macroestructurales, considerando la percepción singular del migrante con relación a las determinaciones históricas, políticas, económicas, sociales y culturales implicadas tanto en el lugar de origen como en el de destino. Con este fin, se realizó una revisión bibliografica acerca de las contribuciones históricas de algunos importantes autores del tema migratorio, además de la diferenciación entre las principales teorías desarrolladas sobre ese fenómeno, para que sea posible la comprensión del enfoque propuesto y su relación con los estudios migratorios.
\end{abstract}

Palabras clave: migración, teorías, Psicología Social Crítica, identidad.

A mobilidade humana é um traço característico que aparece, sob diferentes formas, ao longo da história da humanidade, desde os nômades que se deslocavam em busca de sua sobrevivência até as complexas migrações internacionais atuais. A despeito de ser um tema tão antigo e estudado por diferentes enfoques, o fenômeno migratório vem despertando um interesse cada vez maior de governantes, estudiosos e sociedade civil nas últimas décadas. A relevância que vem assumindo no cenário mundial leva alguns a sugerirem que vivemos na era das migrações, e que o fenômeno migratório contemporâneo assumiu uma complexidade sem precedentes, marcado pela globalização, diferenciação, aceleração e crescente politização das migrações (Cavalcanti, 2015).

A esse respeito, cabe explicitar que, segundo o dicionário online Michaelis (2009), migração alude ao movimento espacial de um povo ou multidão ao passar de um lugar para outro, de forma que migrante se torna um termo frequentemente usado para definir, de modo geral, toda pessoa que se muda do seu lugar de residência habitual para outra região ou país. Não obstante tais definições gerais, existem diversos termos específicos que são utilizados para classificar os processos migratórios, como a diferenciação entre migrações internas (ocorridas no interior de um mesmo país) e as 
migrações internacionais (que se caracterizam pela fixação em outros países), além da distinção no que diz respeito ao tempo envolvido, sendo caracterizadas como permanente, temporária ou sazonal. As migrações podem ainda ser denominadas como espontâneas ou forçadas, quando há causas alheias à vontade do migrante que o forçam a migrar, como ameaças à vida ou à subsistência por razões naturais ou humanas (Centro Scalabriniano de Estudos Migratórios, 2011).

Mais do que terminologias, essas caracterizações evidenciam que "o espaço dos deslocamentos não é apenas um espaço físico, ele é também um espaço qualificado em muitos sentidos, socialmente, economicamente, politicamente, culturalmente" (Sayad, 1998, p.15). Denunciam, portanto, a necessidade de um posicionamento crítico capaz de situar as produções acadêmicas em um sentido político. Por conseguinte, este artigo foi desenvolvido a partir da perspectiva da chamada "Psicologia Social Crítica", assim denominada por seu comprometimento com a realidade brasileira e com os projetos de vida individuais e sua indissociação da dinâmica dos processos histórico-sociais, na busca pela transformação da sociedade (Lima, Ciampa, \& Almeida, 2009).

Toma como base o sintagma identidade-metamorfose-emancipação, desenvolvido por Antônio da Costa Ciampa (Lima \& Ciampa, 2012), para discutir a necessária desnaturalização do termo migrante, cuja vivência singular sempre será atravessada por referências de classe, gênero, raça/etnicidade e nacionalidade. Assim, explicita-se o imperativo de um deslocamento de olhar do processo migratório em si para o migrante que, enquanto sujeito, atribui significados e sentidos particulares aos diversos condicionamentos a que está exposto, fundamentado em suas histórias e projetos de vida pessoais e familiares.

Em vista disso, o presente trabalho propõe uma perspectiva que possibilite a superação das dicotomias existentes entre as abordagens micro e macroestruturais, levando em consideração a percepção singular do migrante no que tange às determinações históricas, políticas, econômicas, sociais e culturais envolvidas tanto no lugar de origem quanto de destino. Para tanto, parte de uma revisão bibliográfica acerca das contribuições históricas de importantes autores da temática migratória, caracterizando e distinguindo as teorias mais relevantes desenvolvidas sobre esse fenômeno, para que seja possível a apreensão da abordagem proposta e sua relação crítica com os estudos migratórios. 


\section{As diferentes teorias acerca do fenômeno migratório}

Ravenstein pode ser considerado pioneiro nos estudos sobre migração, ao desenvolver uma teoria que buscava explicar e caracterizar os elementos motivadores dos movimentos migratórios. Em seu primeiro estudo, datado de 1885 , enumera o que denomina "leis da migração" que, embora contestadas e elaboradas posteriormente, constituem-se como fundamento dos modelos de atração e repulsão. Partindo de suas proposições, Lee (como citado em Gonçalves, 2009) acrescenta que, além dos fatores positivos de atração do lugar de destino e dos fatores negativos de repulsão do lugar de origem, há fatores intervenientes que interferem na decisão de migrar, como as leis migratórias, os custos envolvidos com a viagem, os obstáculos físicos e naturais, a distância e os aspectos individuais.

A partir das elaborações desses dois autores uma série de abordagens teóricas começou a ser desenvolvida para caracterizar a imigração sob diferentes enfoques: demográfico, econômico, político, psicológico, sociológico, entre outros (Gottardi, 2015). A esse respeito, Patarra (2006) explicita que, na década de 1990, o então Comitê de Migração Internacional da IUSSP (do inglês International Union for the Scientific Study of Population) elaborou um documento de revisão e avaliação das diversas teorias de migração existentes, dividindo-as em duas categorias: modelos que descrevem o início do movimento internacional contemporâneo e modelos que explicam a continuidade dos fluxos migratórios no tempo e no espaço. Sendo assim, as teorias da primeira categoria serão divididas em duas grandes abordagens: a micro, que explana os movimentos migratórios sob a ótica do indivíduo; e a macro, que considera a migração como resultado de fatores histórico-estruturais e analisa sob a ótica dos grupos sociais. Já na segunda categoria, que avalia a persistência dos movimentos migratórios, será aqui explicitada a teoria de redes.

\subsection{Perspectiva microestrutural}

Como o modelo de atração e repulsão não consegue explicar o porquê, diante das mesmas condições e contextos, determinadas pessoas migram e outras não, a perspectiva neoclássica concebe que esta decisão é feita com base na análise dos custos e benefícios esperados pelos sujeitos em comparação ao local de origem e destino, ou seja, a decisão é definida a partir de um olhar micro. Nessa abordagem, a migração é causada pelas diferenças salariais existentes entre os países, e os mercados de trabalho são os mecanismos primários de indução dos fluxos internacionais, de modo que a migração possibilitaria um equilíbrio de renda e emprego entre 
diferentes países (Harris \& Todaro, 1970). A migração é, portanto, entendida como a simples somatória de pessoas que se movem por conta do diferencial de renda.

De acordo com Gonçalves (2009), dentro da visão neoclássica, a chamada teoria da modernização destaca as decisões racionais e econômicas progressivas dos migrantes com base nos diferenciais de terra, trabalho e capital entre os países emissores e receptores. 0 modelo de custo e benefício, desenvolvido por Massey, baseia-se na equação que considera os custos do processo migratório e os ganhos esperados no destino, sendo que a migração ocorrerá quando o retorno esperado for positivo, ou seja, quando os benefícios do local de destino forem maiores que os do local de origem. "No entanto, estes ganhos individuais carregam certa subjetividade, pois o peso dado aos custos e aos benefícios esperados cabe apenas ao indivíduo e podem variar de um indivíduo a outro" (Gottardi, 2015, p. 17).

Um modelo semelhante foi desenvolvido por Mincer, porém o autor diferencia as decisões individuais e familiares, argumentando que as famílias tendem a migrar menos que indivíduos sozinhos, já que a decisão passa a ser interdependente a outras pessoas. Da mesma forma, Harbison analisa que o papel exercido pelo sujeito dentro da família é fundamental na decisão de migrar, assim como o tamanho e a composição da família, além dos estágios do ciclo da vida - homens jovens e solteiros tendem a ter uma maior probabilidade de migrar, enquanto a presença de filhos em idade escolar diminuiria tal probabilidade (Santos, Barbieri, Carvalho, \& Machado, 2010).

Conforme explicitam Sasaki e Assis (2000), dentro do modelo microeconômico ainda é possível considerar a existência de uma outra abordagem, baseada no funcionamento do mercado de trabalho, denominada teoria do capital humano. Esse modelo também é apoiado na avaliação de custos e benefícios, no qual o indivíduo avalia os investimentos realizados em sua educação formal, formação profissional e aquisição de conhecimentos de modo geral, relacionando-os com os benefícios futuros que espera receber. Nesse sentido, a migração é vista como um investimento que não trará benefícios imediatos, já que o indivíduo não terá as competências necessárias para competir com os nativos, como o bom domínio do idioma local, mas que servirá de estímulo para o seu desenvolvimento. Os teóricos dessa abordagem defendem, ainda, que as regiões nas quais a taxa de retorno de capital humano é maior, tendem a atrair pessoas mais qualificadas, enquanto que as áreas com menor taxa de retorno, tendem a atrair indivíduos menos qualificados. 


\subsection{Perspectiva macroestrutural}

Diferentemente das teorias anteriormente mencionadas, a abordagem Histórico-Estrutural explica os movimentos migratórios com suporte em uma perspectiva ampla, considerando que a imigração deve ser analisada como parte de um sistema, cujos determinantes são interdependentes e, portanto, não podem ser analisados separadamente. Neste modelo macro, muitas vezes associado a autores marxistas, o contexto econômico e social do indivíduo é mais importante para analisar as causas da migração do que a microanálise de custos e benefícios.

Para Singer (1987, p. 31), as migrações "são sempre historicamente condicionadas, sendo o resultado de um processo global de mudança, do qual elas não devem ser separadas". Nesta perspectiva, o autor demonstra que as migrações estariam diretamente associadas ao desenvolvimento do capitalismo e seriam condicionadas por características estruturais da industrialização, como a modernização e a alteração dos modos de produção. O principal motivo das migrações seriam as desigualdades regionais, que definiriam as áreas de origem dos fluxos e as de destino, estas sendo determinadas, sobretudo, pela demanda por força de trabalho.

Dessa forma, a principal motivação para migrar seriam as oportunidades econômicas e a possibilidade de melhor remuneração do que o indivíduo poderia receber em seu local de origem. Por fim, o autor destaca que, entre o migrante e tais oportunidades econômicas, há uma série de obstáculos possíveis, tais como a baixa qualificação do sujeito e sua insuficiência de recursos - muitas vezes chegando ao local de destino endividado - e, principalmente, a oferta de trabalho maior que a demanda. A primeira condição é passageira e tende a se estabilizar, enquanto a segunda pode gerar a marginalização de parte dos migrantes, que fariam parte do exército industrial de reserva inerente ao capitalismo.

Seguindo a visão macro, Germani (1974, p. 143) defende que o modelo que for empregado para análise da migração "deve levar em conta não apenas fatores expulsivos e atrativos, como também as demais condições sociais, culturais e subjetivas em que tais fatores operam, tanto no que diz respeito ao lugar da residência, como no que diz respeito ao lugar de destino". Sendo assim, a análise da migração deve ocorrer em três níveis: ambiental, normativo e psicossocial. O nível ambiental engloba além dos fatores expulsivos e atrativos, a comunicação, a acessibilidade e o contato entre o lugar de origem e o de destino. O nível normativo é composto pelos papéis, expectativas e padrões de comportamentos institucionalizados na sociedade de origem, que fornecerão o referencial para o indivíduo avaliar suas condições objetivas, facilitando ou dificultando a decisão de migrar. O nível psicossocial leva em consideração as atitudes e 
expectativas dos sujeitos concretos. Segundo o autor, em uma sociedade completamente integrada, o nível psicossocial deve corresponder ao nível normativo, de modo que os padrões do grupo social tenham sido devidamente internalizados pelo indivíduo. 0 mesmo esquema de análise pode ser aplicado também ao processo de adaptação do indivíduo à sociedade de destino, na qual tanto as condições objetivas - oportunidades de emprego, moradia, entre outros - como as normas, crenças e valores que caracterizam os grupos sociais que a compõem, serão determinantes no que diz respeito à recepção dada ao migrante e sua consequente integração.

\subsection{Teoria de redes}

No que diz respeito à persistência dos movimentos migratórios, uma das mais importantes abordagens é a teoria de redes. Dornelas (2001) nos lembra que a rede social é a realidade embrionária de qualquer grupo humano e que é a partir da rede de relações sociais que o sujeito constrói sua identidade. Em vistas disso, defende que "é no âmbito da rede que o projeto migratório se enuncia, assim como também é aí que se mobilizam os recursos e as estratégias para sua concretização" (Dornelas, 2001, p. 6).

De acordo com este modelo, as migrações estão associadas a ligações prévias entre os países de origem e de destino, ligações estas que podem ser de ordem colonial, cultural, comercial, política, militar ou outra, não aludindo obrigatoriamente a uma proximidade física. Além disso, está de acordo com a abordagem proposta por este artigo, pois considera tanto o migrante como tomador de decisões quanto as diversas inter-relações existentes entre as estruturas condicionantes do processo migratório, avaliando não apenas as variáveis econômicas, políticas e sociais, mas também as variáveis familiares, culturais e ambientais (Gonçalves, 2009).

A esse respeito, Santos et al. (2010) expõem que, a contar do momento em que a rede entre duas regiões se estabelece definitivamente, o processo migratório se autoperpetua e tende a se reduzir apenas a partir de um certo desenvolvimento do país de origem - demonstrando a dificuldade para o país de destino restringir os fluxos migratórios quando existe uma rede social que os sustente e os promova. Desse modo, o crescimento das redes sociais minimiza os custos e os riscos dos movimentos migratórios, fazendo com que tais movimentos se tornem independentes dos fatores que os originaram, ou seja, mesmo que inicialmente tenham sido determinantes as diferenças salariais, os níveis de emprego ou qualquer outro fator, à medida em que as redes sociais se estabelecem, elas se tornam determinantes na escolha de algumas regiões em detrimento de outras. 
Outro conceito importante quando o assunto são as redes sociais no processo migratório refere-se ao "capital social", que se constitui precisamente quando há redes e ligações entre indivíduos com o objetivo de acessar ou manter determinados recursos, seja para atingir um bem coletivo ou objetivos individuais, como obtenção de um emprego, desenvolvimento educacional, entre outros (Pacífico, 2008). A utilização desse conceito aponta para a importância das redes sociais não só na decisão de migrar, mas, sobretudo, na recepção e inserção dos migrantes na sociedade de destino. Assim sendo, a produção do capital social pelos imigrantes se mostra fundamental para seu acolhimento inicial, para a busca de moradia e emprego, para o acesso à língua local e aos serviços públicos, além de ser primordial na integração destes, por meio da diminuição dos efeitos nocivos da estigmatização e xenofobia sofridos frequentemente (Dornelas, 2001).

Seguindo esse pensamento, Pacífico (2008) defende que a formação de capital social na sociedade de destino, baseada na formação de relações sociais de confiança e cooperação, é primordial para que o migrante se sinta como cidadão e assim seja reconhecido pelos demais. Para que isso ocorra, a autora defende ser fundamental o desenvolvimento de políticas públicas que levem em consideração a bagagem cultural e as especificidades de cada grupo migrante. Além disso, são justamente as trocas simbólicas - que renovam as alianças e reforçam as obrigações - que mantêm a rede ativa, tanto entre aqueles que migraram quanto com os que ficaram.

As redes demonstram, assim, que "os migrantes mantêm múltiplas relações tanto na sociedade de destino quanto na de origem. Estas relações sugerem características que apontam para 0 contexto transnacional dos fluxos migratórios contemporâneos" (Sasaki \& Assis, 2000, p. 12). Do mesmo modo, Gonçalves (2009) defende que, por conta do desenvolvimento das novas tecnologias de informação e dos meios de transporte, os migrantes não são mais enraizados em um único local - pelo contrário, movem-se entre fronteiras internacionais e culturas sociais, adotando estratégias de vida multiculturais.

\section{Identidade em questão no processo migratório}

Partindo da concepção básica de que toda identidade é uma questão social, política e ideológica, constituindo-se como metamorfose em busca de emancipação (Lima \& Ciampa, 2012), a importância das contribuições de Antonio da Costa Ciampa, ao teorizar o sintagma identidade-metamorfose-emancipação, aparece relacionada, sobretudo, ao contínuo entre socialização e individuação, que torna impossível pensar em identidade como algo estático, fixo e 
cristalizado, totalmente determinado pelo grupo ou pelo contexto no qual se encontra ou completamente livre de determinações.

\subsection{0 sintagma identidade-metamorfose-emancipação}

Conforme defendido por Ciampa (2005), identidade é uma questão que ultrapassa os interesses meramente acadêmicos e científicos, uma vez que "cada indivíduo encarna as relações sociais, configurando uma identidade pessoal. Uma história de vida. Um projeto de vida. Uma vida-que-nem-sempre-é-vivida, no emaranhado das relações sociais" (Ciampa, 2005, p. 132). Seguindo o mesmo pensamento, Almeida (2005) afirma que a questão identitária mostra-se como uma ferramenta fundamental para a compreensão tanto dos processos que induzem a conformidade e a mesmice, quanto dos processos que levam ao entendimento e à autonomia.

Parte-se, então, da compreensão de que o sujeito não nasce humano, mas humanizável, em um mundo previamente humanizado. Deste modo, a identidade resulta tanto do processo de socialização como do processo de individuação, estabelecendo uma relação entre diferenciação social e individuação progressiva, que implica a construção de uma história de vida consciente de si. Neste cenário, a subjetividade é vista sempre articulada com a objetividade da natureza, a normatividade da sociedade e a intersubjetividade da linguagem (Ciampa, 1997a).

Essa relação está presente desde a imputação do nome próprio até a atribuição dos papéis sociais, trazendo à tona a diferenciação entre identidade pressuposta, posta e reposta, pela qual o autor expressa a representação prévia do indivíduo, o aspecto operativo e comportamental da identidade - estabelecido como consequência das relações sociais - e sua reposição contínua. Nesse processo, a identidade passa a ser representada, frequentemente, por substantivos que criam a ilusão de uma substância da qual o indivíduo seria dotado, embora a manifestação do ser seja sempre uma atividade no mundo, em relação com outros (Ciampa, 2005).

A aparência de não metamorfose é denominada por Ciampa (2005) de "mesmice", que ocorre justamente quando a reposição da identidade pressuposta é compreendida como manifestação de uma identidade atemporal, permanente e estável, retirando seu caráter processual e histórico e se aproximando da noção de mito que prescreve as condutas adequadas para reproduzir o social. O eu serposto passa a identificar o sujeito como dotado de certas predicações, de acordo com as quais ele deve agir e ser tratado. Não obstante, o autor esclarece que é sempre o trabalho de re-posição que sustenta a mesmice, podendo esta ser resultado de um esforço pessoal para protelar certas transformações ou ser consequência de uma imposição do capital. 
A identidade, individual ou coletiva, é sempre a história de nossa metamorfose em busca de emancipação que nos humanize. A emancipação, que dá o sentido ético à metamorfose, pode ser impedida ou prejudicada pela violência, pela coerção, invertendo a metamorfose como desumanização. É assim que se revela a natureza intrinsecamente política da identidade. A destruição, a degradação e a indignidade de pessoas e grupos são formas de metamorfose, em última análise, provocadas de modo heterônomo por um poder interiorizado subjetivamente e - ou apenas - exteriorizado objetivamente. (Ciampa, 2003, pp. 3).

Com essa afirmação, demonstra-se que a identidade se apresenta sempre como metamorfose, sem esquecer que "de um lado, portanto, o homem não está limitado no seu vir-a-ser por um fim preestabelecido (como a semente); de outro, não está liberado das condições históricas em que vive, de modo que seu vir-a-ser fosse indeterminação absoluta" (Ciampa, 2012, p. 71-72). Nessa dialética, o ser-para-si não implica a ilusão de uma ausência de determinações externas, mas a busca pela autodeterminação, por meio de uma atividade transformadora de si e do mundo ao seu redor.

Assim, a importância do reconhecimento aparece como último ponto nas ideias centrais defendidas pelo autor, resumidas da seguinte maneira:

a) a constituição do sujeito se dá em e a partir de sua inserção em uma rede de interações mediadas pela linguagem; b) a identidade humana como metamorfose é o processo permanente que se dá ao longo da socialização; c) a individuação, que se dá através da socialização, depende do e está associada ao crescimento da autonomia pessoal; e d) a concretização de uma pretensão identitária de um indivíduo, como expressão de autonomia, pressupõe 0 seu reconhecimento por outros indivíduos (Lima \& Ciampa, 2012, pp. 15).

\subsection{0 ser/estar migrante: as metamorfoses das metamorfoses}

De acordo com a exposição acima, pretende-se demonstrar como a discussão da identidade, na perspectiva inaugurada por Ciampa, pode ser usada para uma compreensão crítica do processo migratório, superando as dicotomias existentes entre os principais modelos de estudo, ao possibilitar um olhar tanto para as questões macro como determinações exteriores, quanto para as questões micro no que tange ao processo de metamorfose em busca de emancipação. 
Nesse sentido, compreender o sujeito imigrante implica, necessariamente, compreendê-lo primeiramente como emigrante, uma vez que "o imigrante só existe na sociedade que assim o denomina a partir do momento em que atravessa suas fronteiras e pisa seu território; o imigrante 'nasce' nesse dia para a sociedade que assim o designa" (Sayad, 1998, p. 16). O autor explana a tendência etnocêntrica de ignorar tudo o que veio antes desse momento e transformar o personagem "migrante" em único representante da identidade daquele sujeito.

Assim, em condições de mudanças pessoais e sociais, sobretudo as contrastivas como a migração, as questões identitárias adquirem especial relevância, evidenciando os paradoxos entre identidade e alteridade, passado e futuro.

Mudar para um local de cultura distinta representa uma ruptura expressa desse quadro de referência, de sentido e pertencimento. A mudança de país impõe ao migrante múltiplas perdas, já que deixa para trás familiares, amigos, trabalho, ambiente físico, língua, normas sociais, locais conhecidos e memória social. Somado a isso, tem de ajustar-se a um novo local, aprender novos códigos sociais, pois sua forma de agir não mais corresponde ao entorno. O que antes era parte da rotina torna-se um desafio diário. (Dantas, 2015, pp. 77).

Para compreender o que leva um sujeito a deixar seu país rumo a um lugar estranho e desconhecido, torna-se imprescindível a compreensão de que, embora 0 indivíduo seja um ser de possibilidades, a sua humanização e a consequente concretização dessas possibilidades dependem das condições históricas e sociais que o circundam. Logo, é possível inferir que o processo migratório é percebido por muitos sujeitos como uma forma (ou única forma - no caso das migrações forçadas) de buscar essa humanização e de concretizar suas possibilidades enquanto seres humanos.

Ciampa (1997b, p. 1) entende a questão da metamorfose humana como "a progressiva e interminável concretização histórica do vir-aser-humano, que sempre se dá como superação das limitações das condições objetivas existentes em determinadas épocas e sociedades". Reforça, ainda, que as metamorfoses também se metamorfoseiam, produzindo uma grande diversidade de possibilidades de acordo com as condições históricas e sociais disponíveis. Assim, no caso dos imigrantes, é possível pensar em metamorfoses das metamorfoses, na medida em que se alteram as condições nas quais o sujeito está inserido, ou seja, migra-se de um país com um conjunto de determinações para outro com determinações totalmente diferentes, gerando novas possibilidades e 
impossibilidades como consequência da união entre subjetividade e objetividade.

A esse respeito, Trad (2003) defende que o processo migratório produz uma ruptura com a familiaridade acrítica, diante de uma realidade cotidiana que se impunha como natural e inquestionável. Ou seja, a não familiarização com o novo ambiente acaba por aguçar a percepção, fazendo com que o sujeito possa refletir sobre fatos e fenômenos aos quais está submerso de uma forma mais crítica e distanciada. Stuart Hall (2015) corrobora com esse pensamento ao discutir a oscilação, decorrente do processo migratório, entre "tradição" e "tradução" e que representaria a emergência de identidades "em transição" ou identidades "recriadas".

Elas carregam os traços das culturas, das tradições, das linguagens e das histórias particulares pelas quais foram marcadas. A diferença é que elas não são e nunca serão unificadas no velho sentido, porque elas são, irrevogavelmente, o produto de várias histórias e culturas interconectadas, pertencem a uma $e$, ao mesmo tempo, a várias "casas" (e não a uma "casa" particular). As pessoas pertencentes a essas culturas híbridas têm sido obrigadas a renunciar ao sonho ou à ambição de redescobrir qualquer tipo de pureza cultural "perdida" ou de absolutismo étnico. Elas estão irrevogavelmente traduzidas. (Hall, 2015, pp. 52).

Cabe ressaltar que esse processo não é linear nem unilateral, estando intrinsecamente relacionado com o reconhecimento obtido diante da identidade pretendida, ou como afirmam Portugueis e Cardoso (2016, p. 160), "inventar o novo a partir do contato com o outro dependerá também da relação de significação imposta pelos olhares (representações) existentes na relação". Assim, um reconhecimento perverso (Lima, 2009) pode neutralizar o potencial emancipatório e reduzir as identidades a personagens fetichizadas.

Obviamente esse reconhecimento perpassa muitas variáveis, sobretudo as relacionadas com a classe, gênero, raça/etnicidade e nacionalidade do migrante. Além disso, há uma diferenciação clara, tantos nas políticas quanto no imaginário social, entre os migrantes econômicos - sobretudo os advindos de países brancos e desenvolvidos - que são vistos como sujeitos que irão contribuir com o crescimento do país de destino, e os migrantes forçados - com ênfase aos advindos de países negros e pobres - estereotipados enquanto invasores, sem nada a acrescentar, taxados como ameaças por "roubar os empregos" e "usufruir dos benefícios sociais" e ainda como perigosos, associando-os à violência e às doenças epidêmicas presentes nos países de origem (como a cólera no Haiti e a febre amarela nos países africanos). 
Dessa forma, no processo de auto apresentação e reconhecimento, os dois movimentos da identidade são possíveis de serem vivenciados pelos imigrantes: alguns experienciam 0 aprisionamento a "mesmice", o fetiche da personagem "migrante-invasor" ou "migrante-indesejável", gerando a má infinidade na qual as contradições são apenas re-postas e não há a concretização no sentido emancipatório da identidade. Como exemplo, é possível citar os migrantes que se sujeitam a trabalhos desumanos, em condições quase escravas, ou ainda os que deixam o país de destino escolhido, justamente porque se sentiram impedidos pelo sistema de se desenvolver e partem em busca de um lugar onde isso seja possível. Outros imigrantes conseguem superar as contradições impostas e construir novas formas de se relacionar com 0 mundo, experienciando a chamada "mesmidade". Podemos dizer que esses sujeitos conseguiram superar a política de identidade que Ihes foi imposta - que os imigrantes devem ser subalternos, aceitar qualquer coisa que lhes for oferecida, já que os nacionais estão fazendo o favor de recebê-los - e, aos poucos, podem vir a desenvolver uma identidade política, uma vez que a individuação é um processo.

\section{Considerações Finais}

Diante da constante complexificação do fenômeno migratório contemporâneo e da multiplicidade de enfoques que ele engloba, este artigo busca apontar perspectivas e relações, fundado na premissa de que o singular materializa o universal na unidade do particular (Ciampa, 2005). Isto posto, deslocar o olhar para o sujeito migrante e compreendê-lo dialeticamente enquanto produto e produtor da história e da sociedade a qual pertence, possibilita superar as dicotomias apresentadas pelas abordagens micro e macroestruturais. Além disso, compreender a identidade enquanto questão social, política e ideológica revela a importante contribuição da Teoria das Redes no estudo do fenômeno migratório, desde a decisão de migrar até a integração do migrante à sociedade de destino.

A contribuição da proposta de desnaturalização do termo migrante, considerando a vivência singular de cada grupo ou sujeito, aparece também na formulação de políticas públicas específicas, que promovam a efetiva inclusão social e produtiva do migrante, considerando sua especificidade e bagagem cultural. Afinal, quem deixa suas origens rumo ao desconhecido parte em busca de algo que não encontra mais em seu habitat, uma experiência emancipatória associada à busca de autonomia, da autodeterminação de pensar e ser e do reconhecimento de ser alguém senhor de si próprio.

Expressa-se, assim, o possível sentido emancipatório do movimento de metamorfose humana, por meio da constante busca de superação 
das limitações objetivas, que muitas vezes impedem ou impossibilitam a concretização histórica do vir-a-ser-humano. A imigração, enquanto processo de negação da negação, torna possível metamorfoses das metamorfoses, uma vez que, ao alterar as condições históricas e sociais nas quais o sujeito está inserido, permite a alterização da identidade pressuposta e o desenvolvimento de uma identidade posta como metamorfose constante.

O processo migratório proporciona, pois, uma ruptura com a reposição irreflexiva do cotidiano e com a familiaridade acrítica e inquestionável que, por sua vez, pode resultar na vivência de processos de autoentendimento e na busca constante para transformar as determinações exteriores em autodeterminação. A existência de um projeto de vida autêntico é primordial para essa construção, assim como as especificidades da história de vida de cada sujeito, na qual as experiências prévias de reconhecimento, as vivências atuais de desrespeito, a formação do capital social e o fortalecimento da identidade coletiva mostram-se fundamentais no enfrentamento da assimilação e no desenvolvimento de um movimento de integração, pautado no respeito e no reconhecimento mútuo.

Ademais, esse processo de metamorfoses das metamorfoses provocado pela migração acaba por gerar identidades híbridas, recriadas a partir da tradição, mas traduzidas às novas relações. Essa hibridização, estabelecida mediante um novo equilíbrio entre a tradição e a originalidade, suscita um sentimento de cidadania universal, uma representação de si como cidadão do mundo que libera o imigrante das amarras de pertencer a um ou a outro lugar e busca em seu agir uma prática transformadora de si e do mundo. Desse modo, a imigração traz consigo novas possibilidades identitárias que, se forem construídas com mais autonomia e consciência política, podem possibilitar o desenvolvimento de fragmentos emancipatórios.

\section{Referências}

Almeida, J. A. M. (2005). Sobre a anamorfose: identidade e emancipação na velhice (Tese de Doutorado). Pontifícia Universidade Católica de São Paulo, São Paulo, Brasil.

Cavalcanti, L. (2015). Imigração e mercado de trabalho no Brasil: Características e tendências. In L. Cavalcanti, A. T. Oliveira, \& T. Tonhati (Orgs.), A inserção dos imigrantes no mercado de trabalho brasileiro (pp. 35-47). Brasília: Cadernos do Observatório das Migrações Internacionais. 
Centro Scalabriniano de Estudos Migratórios. (2011). Breve Glossário sobre Migração e Pastoral. Recuperado de http://www.csem.org.br/verbetes

Ciampa, A. C. (1997a, Setembro). Identidade humana e as metamorfoses das metamorfoses. Comunicação apresentada no Simpósio "Metamorfoses da Identidade no mundo contemporâneo" do Encontro Nacional da ABRAPSO, Belo Horizonte, MG.

Ciampa, A. C. (1997b, Julho). As metamorfoses da "metamorfose humana": uma utopia emancipatória ainda é possível hoje?. Comunicação apresentada no Simpósio "Metamorfoses da Identidade no mundo contemporâneo" do XXVI Congresso Interamericano da Sociedade Interamericana de Psicologia, São Paulo, SP.

Ciampa, A. C. (2003). A identidade social como metamorfose humana em busca da emancipação: Articulando pensamento histórico e pensamento utópico. Texto de Conferência apresentada no XXIX Congresso Interamericano da Sociedade Interamericana de Psicologia, Lima Peru.

Ciampa, A. C. (2005). A estória do Severino e a história da Severina: Um ensaio de psicologia social (10. ed.). São Paulo: Editora Brasiliense.

Ciampa, A. C. (2012). Identidade. In S. T. M. Lane, \& W. Codo (Orgs.), Psicologia Social: O homem em movimento (pp. 5875). São Paulo: Brasiliense.

Dantas, S. D. (2015). Subjetividade e migração: Uma abordagem intercultural profunda a partir da migrações brasileiras. In C. Guanaes-Lorenzi, C. C. L. Motta, L. M. Borges, M. C. Zurba, \& M. D. Vecchia (Orgs.), Psicologia Social e saúde: Da dimensão cultural à político-institucional (pp. 72-91). Florianópolis: Abrapso Editora/Edições do Bosque.

Dornelas, S. M. (2001). Redes sociais na migração: Questionamentos a partir da Pastoral. Travessia, 14(40), 5-10.

Germani, G. (1974). Sociologia da Modernização: Estudos teóricos, metodológicos e aplicados a América Latina (E. L. Figueiredo, Trad.). São Paulo: Mestre Jou.

Gonçalves, M. O. B. (2009). Migrações e Desenvolvimento. Porto: Fronteira do Caos. Recuperado de http://www.cepesepublicacoes.pt/portal/pt/obras/migracoes-edesenvolvimento

Gottardi, A. P. P. (2015). De porto a porto: O eldorado brasileiro na percepção dos imigrantes haitianos em Porto Velho-RO (Dissertação de Mestrado). Pontíficia Universidade Católica do Rio Grande do Sul, Porto Alegre, Brasil. Recuperado de http://repositorio.pucrs.br:80/dspace/handle/10923/7229 
Hall, S. (2015). A identidade cultural na pós-modernidade (12a ed.). Rio de Janeiro: Lamparina.

Harris, J., \& Todaro, M. (1970). Migration, unemployment and development: A two sector analysis. The American Economic Review, 60(1), 126-142. Recuperado de https://www.aeaweb.org/aer/top20/60.1.126-142.pdf

Lima, A. F. (2009). Sofrimento de indeterminação e reconhecimento perverso: Um estudo da construção da personagem doente mental a partir do sintagma identidade-metamorfoseemancipação (Tese de Doutorado). Pontifícia Universidade Católica de São Paulo, São Paulo, Brasil. Recuperado de https://tede2.pucsp.br/handle/handle/17369

Lima, A. F., \& Ciampa, A. C. (2012). Metamorfose humana em busca de emancipação: A identidade na perspectiva da Psicologia Social Crítica. In A. F. Lima (Org.), Psicologia Social Crítica: Paralaxes do contemporâneo (pp. 11-29). Porto Alegre: Sulina.

Lima, A. F., Ciampa, A. C., \& Almeida, J. A. M. (2009). Psicologia social como psicologia política? A proposta de psicologia social crítica de Sílvia Lane. Revista Psicologia Política, 9(18), 223236. Recuperado http://pepsic.bvsalud.org/pdf/rpp/v9n18/v9n18a04.pdf

Michaelis: Moderno dicionário da língua portuguesa. (2009). São Paulo: Editora Melhoramentos. [Dicionário Online]. Recuperado de http://michaelis.uol.com.br/moderno/portugues/index.php

Pacífico, A. M. C. P. (2008). O capital social dos refugiados: Bagagem cultural versus políticas públicas (Tese de Doutorado). Pontifícia Universidade Católica de São Paulo, São Paulo, Brasil. Recuperado de https://tede2.pucsp.br/handle/handle/3969

Patarra, N. L. (2006). Migrações internacionais: Teorias, políticas e movimentos sociais. Revista Instituto de Estudos Avançados da Universidade de São Paulo, 20(57), 7-24. doi:10.1590/S010340142006000200002

Portugueis, D., \& Cardoso, C. M. S. L. (2016). Anamorfose e o sujeito imigrante: Usos do conceito na compreensão das (de)formações identitárias. Revista direitos, trabalho e política social, 2(2), 152-170. Recuperado de http://revista91.hospedagemdesites.ws/index.php/rdtps/article /view/34

Programa de Estudos Pós-Graduados em Psicologia Social (2002). Apontamentos para uma história do Programa de PósGraduação em Psicologia Social: Pontifícia Universidade Católica de São Paulo - 1972-2002. São Paulo: Gráfica da PUC-SP.

Santos, M. A., Barbieri, A. F., Carvalho, J. A. M., \& Machado, C. J. (2010). Migração: Uma revisão sobre algumas das principais teorias. Texto para discussão n.398 (Centro de Desenvolvimento e Planejamento Regional), Universidade 
Federal de Minas Gerais, Belo Horizonte. Recuperado de http://www.cedeplar.ufmg.br/pesquisas/td/TD\%20398.pdf

Sasaki, E. M. \& Assis, G. O. (2000, Outubro). Teorias das migrações internacionais. In ABEP (Org.), Anais eletrônicos do $13^{\circ}$ Encontro Nacional da Associação Brasileira de Estudos Populacionais. Campinas: Unicamp. Recuperado de http://www.abep.org.br/publicacoes/index.php/anais/article/vie $\mathrm{w} / 969 / 934$

Sayad, A.(1998). A imigração ou os paradoxos da alteridade (C. Murachco, Trad.). São Paulo: EDUSP.

Singer, P. (1987). Economia política da urbanização (11a ed.). São Paulo: Editora Brasiliense.

Trad, L. A. B. (2003). Processo migratório e saúde mental: rupturas e continuidade na vida cotidiana. PHYSIS: Revista de Saúde Coletiva, 13(1), 139-156. doi:10.1590/S010373312003000100007

\section{Endereço para correspondência \\ Suélen Cristina de Miranda \\ Pontifícia Universidade Católica de São Paulo \\ Programa de Psicologia Social \\ R. Ministro de Godói, 969, Perdizes, CEP 05015-901, São Paulo - SP, Brasil \\ Endereço eletrônico: suca_miranda@hotmail.com}

Recebido em: 14/02/2019

Reformulado em: 23/06/2019

Aceito em: 03/09/2019

\section{Notas}

* Psicóloga, doutoranda e mestre em Psicologia Social pela Pontifícia Universidade Católica de São Paulo (PUC/SP).

Este artigo de revista Estudos e Pesquisas em Psicologia é licenciado sob uma Licença Creative Commons Atribuição-Não Comercial 3.0 Não Adaptada. 